\title{
EVALUATION OF MASS DRUG ADMINISTRATION FOR FILARIASIS IN BOUDH DISTRICT, ODISHA
}

\author{
Himansu Prasad Acharya1, Subrat Kumar Pradhan², Durga Madhab Satapathy33, Rudra Prasanna Mishra ${ }^{4}$, Upasana Sinha ${ }^{5}$
}

${ }_{1}^{1}$ Associate Professor, Department of Community Medicine, VIMSAR, Burla, Odisha.

${ }^{2}$ Assistant Professor, Department of Community Medicine, VIMSAR, Burla, Odisha.

3 Professor and HOD, Department of Community Medicine, VIMSAR, Burla, Odisha.

${ }_{4}^{4}$ Postgraduate Student, Department of Community Medicine, VIMSAR, Burla, Odisha.

${ }_{5}^{5}$ Postgraduate Student, Department of Community Medicine, VIMSAR, Burla, Odisha.

ABSTRACT
BACKGROUND
Lymphatic Filariasis (LF) is one of the oldest and most debilitating neglected tropical diseases, recognised by World Health
Organisation (WHO) as a group of parasitic infections which primarily affect people living in extreme poverty. Nearly, 2.5 crore
population of Odisha living in 20 endemic districts are at risk with 5 to 10 percent of them suffering from various manifestations of
the disease. Annual Mass Drug Administration (MDA) of single dose of Diethylcarbamazine citrate (DEC) and Albendazole to the
eligible population is carried out to interrupt transmission of the disease.
Objectives- To estimate the coverage of MDA in the households of Boudh district and to enlist the reasons for non-consumption of
the drug.

\section{MATERIALS AND METHODS}

A cross-sectional study was conducted in Boudh district in the month of October 2016. Data was collected from 1547 beneficiaries (300 households of rural and urban combined) in a predesigned, pretested questionnaire and was analysed using MS Excel.

\section{RESULTS}

Among the 1547 beneficiaries in the surveyed population, the coverage of drug consumption among the beneficiaries was $87.9 \%$ (Boudh), 94.9\% (Kantamal) and 85.3\% (Urban). The most common reason for not consuming drugs in both urban and rural area was due to fear of side effects of the drug $(77.04 \%, 70.6 \%$ respectively). Out of 300, 3.6\% households had no information regarding MDA. ASHAs were the source of information in 55.3\% of households followed by AWWs (40.3\%). Side effects due to drugs were present in $2.5 \%$ of rural beneficiaries and $0.2 \%$ of urban beneficiaries.

\section{CONCLUSION}

The MDA coverage in rural areas is more than urban areas. Fear of drugs is the major reason for not consuming the drugs.

\section{KEYWORDS}

Lymphatic Filariasis, MDA, DEC, Evaluation.

HOW TO CITE THIS ARTICLE: Acharya HP, Pradhan SK, Satapathy DM, et al. Evaluation of mass drug administration for filariasis in Boudh district, Odisha. J. Evolution Med. Dent. Sci. 2018;7(13):1584-1587, DOI: 10.14260/jemds/2018/358

\section{BACKGROUND}

Lymphatic Filariasis (LF) is one of the oldest and most debilitating neglected tropical diseases, recognised by the World Health Organisation (WHO) as a group of parasitic infections which primarily affect people living in extreme poverty. ${ }^{1}$ It is caused by lymphatic dwelling nematodes namely Wuchereria bancrofti, Brugia malayi and Brugia timori, and transmitted by the bite of infective mosquitoes. ${ }^{2}$ The most common agent causing LF is W. bancrofti (90\%). ${ }^{2}$ Although LF is not fatal, it can lead to disfigurement, disability and chronic pain, which in turn leads to social stigma and discrimination. As a result, many people suffering from it are unable to lead a socially and economically productive life.

'Financial or Other Competing Interest': Dr. Acharya reports grants from NVBDCP Cell, during the conduct of the study.

Submission 12-02-2018, Peer Review 07-03-2018,

Acceptance 14-03-2018, Published 26-03-2018.

Corresponding Author:

Dr. Subrat Kumar Pradhan

Assistant Professor,

Department of Community Medicine,

VIMSAR, Burla-768017,

Odisha.

E-mail: drsubratpradhan@yahoo.co.in

DOI: $10.14260 /$ jemds $/ 2018 / 358$

\section{(c) $($ ) $\$$}

Lymphatic filariasis infection is found in nearly 120 million people in 83 countries of the world and more than 1.1 billion people are at risk of acquiring infection, which is $20 \%$ of the world's population. Severe disfigurement and disability caused by filariasis are found in over 40 million people and 76 million are apparently normal, but have hidden internal damage to lymphatic and renal systems. ${ }^{3}$ According to the World Health Organisation, 4 countries viz. India, Indonesia, Nigeria and Bangladesh are major contributors (Near about $70 \%$ ) of the infection worldwide. ${ }^{1}$

The Government of India (GoI) began a nationwide MDA campaign in 2004, to cover all the known endemic LF districts with an annual single dose of DEC with an aim of eliminating it as a public health problem by the year 2015 , as stated in the National Health Policy 2002. DEC tablets are available with health workers or volunteers during MDA who make house to house visits and give tablets. Drug distribution booths are also set up at health facilities and other public places during MDA campaign. These tablets are supplied free of cost. Adult female filaria worm lives in body usually for 5-7 years and produces microfilariae, therefore MDA is implemented for $5-7$ years. $^{3}$

In 2007, India changed its strategy from delivery of DEC alone to delivery of DEC plus albendazole. The coverage levels varied from $55 \%$ to $90 \% .{ }^{4}$ Odisha has reported a fall in 
MF rate to 0.77 in 2014 as compared to 2.57 in $2004 . .^{5}$ However, an effective surveillance can help fulfil the aim of global elimination of LF as a public health problem.

Boudh district belongs to western region of Odisha having an area of 3098 sq.km and comprises of 1186 villages distributed among 3 blocks and population density of 142 per sq.km. The total population of district was 441162 (as per 2011 census report), out of which $95.37 \%$ resided in rural area. Literacy rate of the district was $72.51 \%$ as per 2011 census data. 6

\section{With this background knowledge the study was carried} out with the following objectives:

1. To estimate the coverage of MDA in the households in the surveyed districts.

2. To enlist the reasons for non-consumption of the drug.

\section{MATERIALS AND METHODS}

\section{Study Period and Place}

The survey to know the coverage and acceptance of MDA against filariasis in Boudh district of Odisha was conducted by the Department of Community Medicine, VIMSAR, Burla.

Type of Study- Observational study.

\section{Sampling Method \\ Rural Area}

In the first stage, two blocks from Boudh district, Boudh and Kantamal block were randomly selected and in second stage, two sub-centre areas per block i.e. in Boudh block two subcentres viz. Baunsuni and Balasingha and from Kantamal block two sub-centres viz. Manamunda and Ratakhandi were randomly selected. In the third stage, five villages per subcentre area were selected randomly. Within the village ten households were visited randomly and the members available were interviewed. Thus, a total of 200 households from rural area $(10 \mathrm{HH} /$ village $* 5$ villages/ sub-centre area * 2 sub-centre areas/ block $* 2$ blocks/ district) were included in the survey.

\section{Urban Area}

Boudh town was purposively selected and two wards (ward1 and ward-8) in the town were selected randomly and from each ward 50 households were visited randomly (50 HH/Ward* 2 Wards). Thus, in total $300 \mathrm{HH}$ were included in the study.

\section{Study Method}

The data was collected through a door-to-door survey after defining the area and population under study. A verbal consent was taken from each respondent after explaining the objective of the study. Participants who were unwilling to take part in the study along with the pregnant woman and children below 2 years of age were excluded. The questionnaire prepared contained the particulars of the family and few questions regarding distributions, consumption and reasons for non-consumption of DEC and Albendazole tablets. It included questions relating to source of information regarding MDA. Ten houses were covered, starting from one mark or point of a street or lane in a village of a rural area and in urban area fifty houses were covered in the wards.

\section{Data Entry and Analysis}

Data was collected, compiled and analysed using MS Excel.

\section{RESULTS}

Table 1 shows the age and sex wise distribution of beneficiaries of 300 interviewed households. Consumption status of a total of 1547 beneficiaries were enquired from Boudh district. 497 beneficiaries from Boudh block, 571 from Kantamal Block and 479 from Boudh urban area were evaluated. Among them nearly $80 \%$ were above or equal to 15 years of age group. The males and females were almost equally distributed.

Table 2 depicts that in Kantamal block all $(100 \%)$ of the beneficiaries < 15 years had received the drugs, whereas in Boudh block (94.7\%) and in the urban areas (95.6\%) had received the drug in the age group $<15$ years. Similarly, as regards receipt of drugs, in $\geq 15$ years' age group the beneficiaries were 93\%, 99.6\% and $97.1 \%$ in Boudh, Kantamal and urban areas of Boudh districts respectively. The overall receipt of drugs among the beneficiaries was $96.7 \%$ in rural areas and $97.3 \%$ in urban areas of Boudh district.

Table 3 shows that in Boudh block the consumption of drugs in both the age group $<15$ years and $\geq 15$ years, i.e. $84.6 \%$ and $88.7 \%$ respectively. Similarly, in urban area of Boudh the consumption status was $79.3 \%$ in the age group $<15$ years and $85.3 \%$ in the age group $>15$ yrs. But in Kantamal block the consumption status was much better, i.e. almost $95 \%$ in both the age groups.

Table 4 shows that the number of beneficiaries who consumed drugs in front of drug distributor was very less, i.e. only $25.24 \%$ in Boudh, $6.66 \%$ in Kantamal and $8.15 \%$ in urban areas of Boudh. In < 15 years' age group 15.5\% of beneficiaries consumed drugs in front of drug distributor in Boudh as compared to $2.6 \%$ and $5.4 \%$ in Kantamal and urban areas of Boudh respectively. In $\geq 15$ years' age group, the beneficiaries that consumed drugs in front of drug distributor were $27.5 \%, 7.7 \%$ and $8.7 \%$ in Boudh, Kantamal and Urban areas of Boudh respectively.

Table 5 depicts rural and urban distribution among beneficiaries. Among the beneficiaries in the rural areas, $96.7 \%$ received drugs, $88.8 \%$ consumed drugs and $13 \%$ consumed drugs in front of drug distributor. In the urban areas $97.3 \%$ received drugs, $84.6 \%$ consumed drugs and $6.9 \%$ consumed drugs in front of drug distributor. Out of a total 1547 beneficiaries in the Boudh district 96.9\% beneficiaries received the drugs, $87.5 \%$ consumed drugs and $11.11 \%$ consumed the drugs in front of the drug distributor.

Table 6 shows that out of 300, 11 (3.6\%) households had no information regarding MDA. ASHA were the most common source of information, i.e. in $55.3 \%$ of households followed by AWW (40.3\%), ANM (0.3\%) and others (0.3\%), i.e. radio, TV.

Table 7 describes the most common reason for not consuming drugs in both urban and rural area was due to fear of side effects of the drugs (73.3\%) followed by the notion that they are not suffering from LF, so why to take drugs (8.9\%). $7.5 \%$ of them had no information about LF/MDA, $3.4 \%$ were away from home so were not able to take the drugs. $6.9 \%$ gave some non-specific reasons for not consuming the drugs. 


\begin{tabular}{|c|c|c|c|c|c|c|c|c|c|c|}
\hline \multirow{2}{*}{ Age } & \multicolumn{3}{|c|}{ Block I (Boudh) } & \multicolumn{3}{|c|}{ Block II (Kantamal) } & \multicolumn{3}{|c|}{ Urban (Boudh) } & \multirow{2}{*}{ Total } \\
\hline & Male & Female & Total & Male & Female & Total & Male & Female & Total & \\
\hline$<15$ years & 49 & 47 & 96 & 57 & 64 & 121 & 49 & 41 & 90 & 307 \\
\hline$\geq 15$ years & 207 & 194 & 401 & 236 & 214 & 450 & 187 & 202 & 389 & 1240 \\
\hline Total & & 497 & & & 571 & & & 479 & & 1547 \\
\hline
\end{tabular}

\begin{tabular}{|c|c|c|c|c|c|c|}
\hline \multirow{2}{*}{ Age } & \multicolumn{2}{|c|}{ Block I (Boudh) } & \multicolumn{2}{c|}{ Block II (Kantamal) } & \multicolumn{2}{c|}{ Urban (Boudh) } \\
\cline { 2 - 7 } & Beneficiaries & Received & Beneficiaries & Received & Beneficiaries & Received \\
\hline$<15$ years & 96 & $91(94.7)$ & 121 & $121(100)$ & 90 & $88(95.6)$ \\
\hline$\geq 15$ years & 401 & $373(93.01)$ & 450 & $448(99.6)$ & 389 & $378(97.1)$ \\
\hline Total & 497 & $464(93.36)$ & 571 & $569(99.65)$ & 479 & $466(97.28)$ \\
\hline \multicolumn{7}{|c|}{ Table 2. Number of Beneficiaries who Received Drugs (\%) } \\
\hline
\end{tabular}

\begin{tabular}{|c|c|c|c|c|c|c|}
\hline \multirow{2}{*}{ Age } & \multicolumn{2}{|c|}{ Block I (Boudh) } & Block II (Kantamal) & \multicolumn{2}{c|}{ Urban (Boudh) } \\
\cline { 2 - 7 } & Received & Consumed & Received & Consumed & Received & Consumed \\
\hline$<15$ years & 91 & $77(84.6 \%)$ & 121 & $114(94.2 \%)$ & 90 & $73(79.3 \%)$ \\
\hline$\geq 15$ years & 373 & $331(88.7 \%)$ & 448 & $426(95.08 \%)$ & 389 & $332(85.34 \%)$ \\
\hline Total & 464 & $408(87.93 \%)$ & 569 & $540(94.9 \%)$ & 479 & $405(84.55 \%)$ \\
\hline \multicolumn{3}{|c|}{ Table 3. Number of Beneficiaries who Consumed Drugs (\%) } \\
\hline
\end{tabular}

\begin{tabular}{|c|c|c|c|c|c|c|}
\hline \multirow{2}{*}{ Age } & \multicolumn{2}{|c|}{ Block I (Boudh) } & \multicolumn{2}{c|}{ Block II (Kantamal) } & \multicolumn{2}{c|}{ Urban (Boudh) } \\
\cline { 2 - 7 } & Consumed & In Front of DD & Consumed & In Front of DD & Consumed & In Front of DD \\
\hline$<15$ years & 77 & $12(15.5 \%)$ & 114 & $03(2.6 \%)$ & 73 & $04(5.4 \%)$ \\
\hline$\geq 15$ years & 331 & $91(27.5 \%)$ & 426 & $33(7.7 \%)$ & 332 & $29(8.7 \%)$ \\
\hline Total & 408 & $103(25.24 \%)$ & 540 & $36(6.66 \%)$ & 405 & $33(8.15 \%)$ \\
\hline \multicolumn{3}{|c|}{ Table 4. Number of Beneficiaries who Consumed Drugs in Front of Drug Distributor (\%) } \\
\hline
\end{tabular}

\begin{tabular}{|c|c|c|c|}
\hline Residence & Drug Received & Drug Consumed & Consumed Drugs In Front of DD \\
\hline Rural (N=1068) & $1033(96.7)$ & $948(88.8)$ & $139(13)$ \\
\hline Urban (N=479) & $466(97.3)$ & $405(84.6)$ & $33(6.9)$ \\
\hline Total (N=1547) & $1499(96.9)$ & $1353(87.5)$ & $172(11.11)$ \\
\hline \multicolumn{3}{|c|}{ Table 5. Beneficiaries with Rural-Urban Distribution (\%) } \\
\hline
\end{tabular}

\begin{tabular}{|c|c|c|c|c|c|}
\hline Residence & ANM & AWW & ASHA & OTHERS & NO INFO \\
\hline Rural & 1 & 32 & 185 & 1 & 4 \\
\hline Urban & 0 & 89 & 07 & 0 & $11(3.6 \%)$ \\
\hline Total & $1(0.3 \%)$ & $121(40.3 \%)$ & $166(55.3 \%)$ & $1(0.3 \%)$ & \\
\hline \multicolumn{7}{|c|}{ Table 6. Source of Information (n= 300, $\mathbf{H H})(\%)$} \\
\hline
\end{tabular}

\begin{tabular}{|c|c|c|c|c|c|c|}
\hline Reasons & $\begin{array}{c}\text { Fear of Side Effects } \\
\text { of Drugs }\end{array}$ & $\begin{array}{c}\text { Not Suffering from } \\
\text { LF, so why take } \\
\text { Drugs }\end{array}$ & $\begin{array}{c}\text { No Info about } \\
\text { LF/MDA/ DEC }\end{array}$ & $\begin{array}{c}\text { Away from Home } \\
\text { so did not take } \\
\text { Drugs }\end{array}$ & $\begin{array}{c}\text { Other Non-Specific } \\
\text { Reasons }\end{array}$ & Total \\
\hline Rural & $60(70.6 \%)$ & $13(15.3 \%)$ & $8(9.4 \%)$ & $4(4.7 \%)$ & $0(0 \%)$ & 85 \\
\hline Urban & $47(77.04 \%)$ & $0(0 \%)$ & $3(4.9 \%)$ & $1(1.6 \%)$ & $10(16.4 \%)$ & 61 \\
\hline Total & $107(73.3 \%)$ & $13(8.9 \%)$ & $11(7.5 \%)$ & $5(3.4 \%)$ & $10(6.9 \%)$ & 146 \\
\hline \multicolumn{7}{|c|}{ Table 7. Reasons for Not Consuming Drugs after Receiving the Drugs (\%) } \\
\hline
\end{tabular}

\section{DISCUSSION}

In a study conducted in Sagar and Damoh districts of Madhya Pradesh, the coverage rate was $96.2 \%$ and $84 \%$ respectively with a total coverage rate of $90.90 \%$ which is lower compared to this study (96.9\%). A total compliance rate in both the districts was $66.66 \%$. The compliance rate in Sagar district was $85.52 \%$ and was only $42.82 \%$ in Damoh, which were very low in comparison to our study (87.4\%). The most common reason for not consuming the drug was drug given at home, but drug distributor did not ask to take the drug in front of him/ her in 50\% cases. In our study though majority of the beneficiaries (89\%) did not consume the drug in front of the drug distributor, they consumed the drugs of their own. ${ }^{7}$

In another study conducted in a study population of 1228 in Karnataka state, the compliance rate was $78.6 \%$ in
Bagalkot district and $38.8 \%$ in Gulbarga districts which are very low figures in terms of our study findings. ${ }^{8}$

A study done in West Bengal with total eligible population of 683 , among which $98.8 \%$ received the drugs which is as par as our study (96.9\%). About $5 \%$ of the recipients did not consume the drugs compared to nearly $10 \%$ recipients in our study. The drug compliance rate was significantly lower in urban $(90.7 \%)$ than in the rural areas (95.7\%) compared to $88.8 \%$ and $84.6 \%$ respectively in our study. ${ }^{9}$

In another study done in Puri district, Odisha nearly $99 \%$ of the studied individuals in both rural and urban areas received DEC and Albendazole during the MDA campaign. However, only $28 \%$ in rural areas and $31 \%$ in urban areas had consumed the distributed drugs. These findings were quite lower compared to our study. ${ }^{10}$ 


\section{CONCLUSION}

- The total number of household members surveyed was 1636 , out of which total number of beneficiaries were 1547 (94.6\%).

- Among the beneficiaries $80 \%$ were $\geq 15$ years and above, while $20 \%$ were $<15$ years.

- $\quad$ Females constituted $49 \%$ and males 51\%.

- Among 1547 beneficiaries in the surveyed population, 1499 (96.9\%) had received drugs during MDA.

- $\quad$ Out of the beneficiaries, 1353 (87.45\%) had consumed drugs.

- Out of the beneficiaries who consumed drugs, 172 $(11.12 \%)$ had consumed drugs in front of drug distributor.

- The overall drug consumption rate in Boudh district was found to be $87.4 \%$ among the beneficiaries $187.9 \%$ in Boudh block, $94.9 \%$ in Kantamal block and $85.3 \%$ in Boudh Urban).

- Among the beneficiaries in the rural areas, $96.7 \%$ received drugs, $88.8 \%$ consumed drugs and $13 \%$ consumed drugs in front of drug distributor.

- In the urban areas $97.3 \%$ received drugs, $84.6 \%$ consumed drugs and $6.9 \%$ consumed drugs in front of drug distributor.

\section{Recommendation}

- Social mobilisation activities on importance of filariasis and role of MDA should be carried out in the community. The use of posters, banners and mass media should be utilised for better coverage of MDA in the district.

- $\quad$ Supervision and monitoring of MDA activities will help not only in boosting the activities of the grass root level health workers, but will also decrease the apprehensions of the community regarding the drugs and their side effects.

- A process evaluation of MDA should be conducted. This includes in-depth interviews among utilisers and nonutilisers, the service providers and the planners of the program both at block and district level. Focus group discussion should also be done among different state holders of the program. This evaluation can reveal the factual position of MDA, so that appropriate steps can be taken for improving the coverage of the program.

\section{Source of Funding}

NVBDCP cell, Odisha.

\section{REFERENCES}

[1] WHO. Lymphatic filariasis. 2017 http://www.who.int/mediacentre/factsheets/fs102/e $\mathrm{n} /$

[2] Park K. Park's Textbook of preventive and social medicine. Communicable diseases. Lymphatic filariasis. 24th edn. Jabalpur: M/s Banarsidas Bhanot 2017: p. 287.

[3] Programme NVBD. Guidelines on elimination of lymphatic filariasis India. 2014: p. 1-108.

[4] Lahariya C, Mishra A. Strengthening of mass drug administration implementation is required to eliminate lymphatic filariasis from India: an evaluation study. J Vector Borne Dis 2008;45(4):313-20.

[5] NVBDCP. National Vector Borne Disease Control Programme - MF Rate 2017. http://www.nvbdcp.gov.in/fil-rate.html

[6] District Census Handbook Baudh. Odisha Series-22. Part XII-B. Directorate of Census Operations Odisha. Census of India, 2011.

[7] Sharma A, Kasar PK. Coverage and compliance of mass drug administration for elimination of lymphatic filariasis in endemic areas of Sagar and Damoh Districts, Madhya Pradesh. Natl J Community Med 2013;4(4):653-7.

[8] Patel PK. Mass drug administration coverage evaluation survey for lymphatic filariasis in Bagalkot and Gulbarga districts. Indian J Community Med 2012;37(2):101-6.

[9] Ghosh S, Samanta A, Kole S. Mass drug administration for elimination of lymphatic filariasis: recent experiences from a district of West Bengal, India. Trop Parasitol 2013;3(1):67-71.

[10] Hussain MA, Sitha AK, Swain S, et al. Mass drug administration for lymphatic filariasis elimination in a coastal state of India: a study on barriers to coverage and compliance. Infect Dis Poverty 2014;3:31. 